\title{
Escutar o desconforto dos corpos que se deslocam para contextos interculturais.
}

\author{
Escuchar el malestar de los cuerpos que se \\ desplazan a contextos interculturales.
}

\section{Listening to the discomfort of bodies moving to intercultural contexts.}

\author{
RITA RAINHO \\ JOSÉ CARLOS DE PAIVA
}

\section{Resumo}

Neste texto es autores interpretam o desconforto resultante da deslocação de seus corpos para relações de educação artística intercultural no Sertão pernambucano, Brasil, e na África, Cabo Verde e Moçambique, desde 1996, no âmbito do movimento intercultural IDENTIDADES. Este movimento nasce ligado à Faculdade de Belas Artes da Universidade do Porto, Portugal, uma instituição de renome internacional e legitimidade brilhante, onde as práticas de educação artística e a investigação têm conduzido os corpos des autores num espaço e tempo de conflitos pessoais, de reconhecimento do colonial que os integra e da necessidade autocrítica de se entenderem, num enfrentamento epistemológico de

\footnotetext{
1Docente e Investigadora do Instituto de Investigação em Arte, Design e Sociedade (i2ADS) da Faculdade de Belas Artes da Universidade do Porto (FBAUP). Doutoramento em Educação Artística (2018), Mestrado em Arte e Design para o Espaço Publico (2011), Licenciada em Belas Artes (2009), pela FBAUP - ritarainho1@gmail.com - https://orcid.org/0000-0003-0741-0435

2 Investigador Integrado do Instituto de Investigação em Arte, Design e Sociedade (i2ADS) da Faculdade de Belas Artes da Universidade do Porto (FBAUP). Doutoramento em Pintura, Mestre em Arte Multimédia, Licenciado em Artes Plásticas pela FBAUP. Coordena o projeto 'IDENTIDADES_Colectivo de Acção e Investigação' (ID_CAI) - jpaiva@fba.up.pt -

https://orcid.org/0000-0002-2084-9437
} 
atenção na escuta e memória sobre as reflexões neste campo.

Palavras-chave: desconforto, decolonialidade, educação artística crítica, escuta, memória.

\section{Resumen}

En este texto es autores interpretan el malestar resultante del desplazamiento de sus cuerpos hacia las relaciones de educación artística intercultural en el interior de Pernambuco, Brasil, y en África, Cabo Verde y Mozambique, desde 1996, en el ámbito del movimiento intercultural IDENTIDADES. Este movimiento nació vinculado a la Facultad de Bellas Artes de la Universidad de Porto, Portugal, una institución de renombre internacional y brillante legitimidad, donde las prácticas de educación artística y la investigación han llevado a los cuerpos des autores en un espacio y tiempo de conflictos personales. desde el reconocimiento de lo colonial que los integra y la necesidad autocrítica de entenderse, en un enfrentamiento epistemológico de atención a escuchar y recordar las reflexiones en este campo.

Palabras clave: malestar, decolonialidad, educación artística crítica, escucha, memoria.

\section{Abstract}

In this text the authors interpret the discomfort resulting from the displacement of their bodies into intercultural art education relations in the Sertão of Pernambuco, Brazil, and in Africa, Cape Verde and Mozambique, since 1996, within the intercultural movement IDENTIDADES. This movement is linked to the Faculty of Fine Arts of the University of Porto, Portugal, an institution of international renown and brilliant legitimacy, where arts education practices and research have led the bodies of the authors in a space and time of personal conflicts, of recognition of the colonial that integrates them and the self-critical need to understand themselves, in an epistemological confrontation attending to the listening and the memory on the reflections in this field.

Key words: discomfort, decoloniality, critical arts education, listening. Memory. 


\section{Introdução}

O trabalho do colono consiste em tornar impossível mesmo os sonhos de liberdade do colonizado. O trabalho do colonizado consiste em imaginar todas as eventuais combinações para aniquilar o colono (FANON, 2015, p. 95).

Toda a experiência de um outro pensamento é uma experiência sobre o nosso próprio (CASTRO, 2018, p. 96).

Somos dois seres distintos e singulares: um dos corpos conformado pela arte, expõe-se ao disforme e deslocado pela necessidade de uma perturbação do individual, do autoral, genial macho vendido ao colonial e capital - atravessando-se por outros caminhos, como o do político e o do educativo; o outro, com um corpo usado de caminhante, teimoso optimista cansado dos seus próprios fracassos, mas persistente na partilha conflituosa com muitos professores/implicados por uma educação artística crítica e inscrita no político, esforços de transformação cúmplice e renovadora das práticas educativas no ensino artístico em escolas portuguesas, brasileiras, cabo-verdianas, moçambicanas.

Integramos o mesmo grupo de pesquisa, o IDENTIDADES_colectivo de acção/investigação ${ }^{3}$, e nos confrontamos de modo agonístico com o que cada um digere na produção de significados que as experiências partilhadas possibilitam, escutando e tecendo cumplicidades com os movimentos existentes, nesses arredores que habitam. A predisposição para a escuta, (e não para o ouvir) e para a construção de memória significativa, sabemos não anular a castração de nossos sentidos e o condicionamento de nossos modos de olhar, inundados por um passado escolar, familiar e social altaneiro, que ignora e despreza o que lhe é externo. Reconhecendo, assim, a mobilização de esforço crítico complementar para a escuta e engajamento na luta contra o exercício de poder das políticas e das culturas discriminatórias, de invizibilização, centradas em_si e a partir_de_si.

Un mundo más femenino que se presenta contra todas las formas de poder, sometimiento y violencia, porque un mundo menos fálico será posiblemente más amoroso (MERLIN, 2019, p. 119).

Todo homem é dois, e o outro é o mais verdadeiro (BORGES, 2001, p. 29).

3 IDENTIDADES MOVIMENTO CULTURAL integrado ao Instituto de Investigação em Arte, Design e Sociedade (i2ADS) da Faculdade de Belas Artes da Universidade do Porto (FBAUP). Disponível em: https:// identidades.up.pt 
Nas muitas e continuadas deslocações esperançosas de ativação crítica, realizadas ao longo de anos, fomos confirmando as limitações da nossa abertura ao desconhecido e de como se tornaram obsoletos e frágeis muitos dos conceitos que se naturalizaram, nos possuem e que transportamos. A deslocação entendida como um abandono do espaço de conforto que nos acolhe, para um desafio iniciador, imprevisível e instigador. Entre as brigas epistemológicas e o desconforto, assumiu presença relevante a ideia de Arte, aprendida nas Escolas Ocidentais e nos Museus globalizados, condescendendo com a força que a arte legitimada pelo poder nos diversos períodos da história consagrou, apagando e menosprezando as artes não_ocidentais e as culturas subalternizadas, e sendo desatentos perante o ostracismo exercido face às atitudes e às práticas de irreverência artística, de crítica ao hegemónico e de cumplicidade com o político das utopias de transformação.

Desconforto, também pelo efeito que o sentido colonizador das práticas educativas comportam, no corolário de como a ideia de uma educação para o bem e para o desenvolvimento foi sendo naturalizada, sem se atender a que a determinação desse bem, correspondia a um propósito de governação dos sujeitos, como passivos e a_críticos perante um mundo pleno de desigualdade e de múltiplas discriminações, e que esse desenvolvimento se condicionava aos modelos do sistema económico e dos interesses gananciosos do capitalismo_global, implicando o esvaziamento da cidadania democrática e participativa na activação de possibilidades de futuro.

O desenvolvimento tem sido constituído como o valor hegemónico que o assume como paradigma de futuros. A interferência internacional sobre os destinos dos países que conquistaram a sua independência, a partir de segunda metade do século XX, desrespeitou completamente as vozes africanas que sabiam que "[...]nenhum povo se desenvolveu unicamente a partir do exterior. Se ele se desenvolve, é porque extrai de si mesmo os elementos do seu próprio desenvolvimento" (KI-ZERBO, 2006, s.p.).

Atende-se aos resultados de anos e anos de narrativas e acções desenvolvimentistas e verifiquem-se os resultados. Roque Amaro, investigador dedicado a estas problemáticas apresenta uma visão esclarecedora:

[...]hoje, do ponto de vista da justiça e da relação entre os níveis de felicidade e de realização entre os povos e entre estes e o seu ambiente, estamos pior que há trinta anos atrás, quando o escândalo das desigualdades e do 'subdesenvolvimento' de largas massas da população deste planeta fez soar as campaínhas de alarme das instituições internacionais, nomeadamente da ONU que, na sequência desse alarme, instituiu, uma após outra, duas 
'décadas de ajuda ao desenvolvimento', saldadas por evidentes e rotundos fracassos (AMARO, 1990, p. 448).

A nossa deslocação das ideias propagandeadas de uma África incapacitada e exótica, para um contacto com a potência endógena, persistentemente bloqueada e com a esperança congelada, permitiram entender a selvagem prepotência civilizacional do Norte, amputando das possibilidades plurais e universais de crescimento global. Séculos de crimes exercidos a partir das tomadas pela força colonial dos territórios, da destruição de reinos ancestrais, desestruturação de povos e comunidades, pela imposição das línguas europeias e pela assimilação forçada das culturas ocidentais. O efeito catastrófico da escravatura exercida durante séculos mutilou as estruturas sociais numa dimensão desmesurada, ainda não reconhecida na sua dimensão, ainda não ressarcida, nem superada.

Sendo certo que a luta anticolonial forjou a independência dos actuais países africanos, é certo e são conhecidas as imposições políticas e administrativas exercidas pelos dispositivos financeiros do capitalismo_global (onde o Banco Mundial assume relevo), que amarraram os destinos nacionais a uma subalternidade, que alimenta as castas políticas criadas nos governos e em seu retorno e perpetuam a pobreza da maioria da população e a discriminação.

[...]Não são eles os culpados. Eu é que os despercebo (CRAVEIRINHA, 1998, p. 117).

O movimento de deslocação acirra os conflitos internos nos nossos corpos, suscitando questionamentos sobre o que considerávamos já confortável na nossa interpretação do que fazemos e sobre os nossos desejos. Reconhecemos serem nossos corpos positivamente tensionados pela atenção crescente dada à escuta, atentos às tensões relacionais com que nos confrontam as comunidades educativas com quem nos fomos relacionando, permitindo-nos perceber que, para além dos olhares que culturalmente carregamos, necessitávamos entender melhor o que se nos era oferecido, e o modo como éramos olhados, como nossos propósitos eram filtrados e analisadas nossas falas e performatividades. Os nossos olhares, as memórias que produzimos são carregadas de uma insuficiência marcada pela amarras interpretativas que os encerram nas concepções construídas, a partir de ideias hegemónicas de uma cultura ocidental fechada dentro de si. Esta limitação não permite ler a força do lugar de fala de quem nos olha de um Sul político, na dimensão da sua história e da sua revolta, evidenciando o que não conseguimos, enquanto corpos brancos, deixar de representar. 
[...]não, não, já não somos nós quem olha - há agora, sim, um olhar que prevalece sobre o nosso, um olhar que nos obriga a segui-lo e a esquecer o que olhávamos, um olhar que dirige o nosso [...] (MARTINS, 2005, s.p.).

A consciência da nossa fragilidade, ainda que reforçada por um esforço anticolonial, inscreve-nos num movimento de tensão nas relações que estabelecemos numa atitude que gostaríamos de usar, mais de escuta que de fala. Sabemos da dificuldade de digerir a complexidade do que nos é permitido vivenciar e o quanto o Sul político incorpora a herança da resistência, da autodeterminação e da independência dos seus povos, mesmo sendo também este Sul composto por lugares e pessoas que receberam a herança do imperialismo e da submissão à supremacia da colonialidade do ser, poder e saber ocidentais.

\section{Risco do diálogo}

O primeiro risco do diálogo é que o nosso interlocutor pode não compreender o que queremos dizer. [...] O segundo risco do diálogo é exactamente o contrário, ou seja, o risco de podermos de facto ser entendidos claramente (APPADURAI, 2009, p. 23-24).

O que nos ocorreu neste movimento de deslocações realizadas durante 25 anos para o Sul político, de escuta - "[...] se não tens tempo para ouvir-me, contarei um outro dia” (BÂ, 2010, p. 183) - e de construção de memória, foi-nos progressivamente prevenindo da tentação salvacionista e paternalista e de resquícios coloniais de que somos portadores, mesmo não o querendo ser. A sociedade onde nos inserimos e que interferiu na nossa construção, está armada de dispositivos sedutores que ocultam valores que passamos a integrar, mesmo que, diferentes dos nossos propósitos políticos. As nossas tensões transportam a percepção dessa incomodidade, dificultando o movimento anticolonial, de libertação em cada um_nós.

\footnotetext{
Nas minhas conversas com homens negros, aprendi muito sobre os vários sistemas de opressão e sobre como eles podem não se reconhecer uns aos outros (ADICHIE, 2015, p. 44).
}

Essas tensões são ampliadas pelo descontentamento crescente com a sociedade ocidental onde se erguem os valores da ganância, e se alargam despuradamente os espaços de discriminação escondidos ou apresentados no simulacro que 
as narrativas de 'combate à pobreza', pelo 'desenvolvimento', na defesa dos 'direitos humanos' transportam.

\begin{abstract}
Pensa-se que a memória já não serve para grande coisa, o que é mau. O tempo gera acumulação de experiência e de sabedoria. Está a deitar-se para o lixo o produto desse lento aumento, que levou séculos a formar. Com tudo o que isso implica de aprendizagem desperdiçada (MATTOSO, 2000, p. 14).
\end{abstract}

A nossa presença corpo a corpo com modos diferenciados de vivenciar a arte e a educação artística, como a insurgência que encontramos no Instituto de Arte, Tecnologia e Cultura (M_EIA), na Neve Insular ${ }^{4}$ e Outros Bairros, em Cabo Verde, a implicação da educação na luta da comunidade quilombola de Conceição das Crioulas, no Sertão pernambucano do Brasil, ou nos esforços de desenvolvimento da Escola Nacional de Artes Visuais (ENAV) -Maputo, Moçambique - e de criação do Instituto Superior de Artes e Cultura, Moçambique (ISArC), em Moçambique, nos permitem verificar os limites de nossos propósitos, reconhecendo o quanto temos de encontrar uma reconfiguração crítica das nossas práticas, epistemologias e ontologias da Educação Artística, considerando o fracasso do modelo educativo que se tornou hegemónico nas escolas artísticas que frequentamos na Europa.

Nos situamos na potência de um trânsito de questionamento e de resiliência agonística vingada nesse Sul político, berço de uma sincera luta anti-colonial. Processo contínuo de procura de conhecimento espelhado, de construção de confiança partilhada e de multiplicação de cumplicidades. Espaço anticolonial de acção intercultural, de valorização da escuta e de sua memorialização, de experimentação aberta, de implicação dos corpos, de inscrição política nas vidas. Espaço imanente de aprendizagem, para cada um_nós.

\title{
Aberturas
}

[...] o mundo é abertura e que o tempo só existe no e pelo esperado inesperado e imprevisível (MBEMBE, 2016, p. 52).

Toda a criança tem capacidade de criar imagens, criar sonoridades, de manusear materiais e criar narrativas de forma espontânea, surpreendente e sobre-

4 Neve Insular é um projeto que pretende cruzar a agroecologia, o educativo, o artístico em torno do algodão, como elemento central na história de Cabo Verde. 
tudo 'livre'. Sontag (1987, p. 41) nos interroga, dizendo que : “[...] a nova sensibilidade entende a arte como extensão da vida - sendo esta entendida como a representação (de novos) modos de intensidade." Não fosse o equívoco de se considerar a educação artística como um lugar para se privilegiarem as crianças e os jovens mais vocacionados para a especialização disciplinar de uma das artes, procurando promovendo a formação de artistas, excluído os outros remetidos a um inibido lugar de espectadores, se poderia promover a presença do artístico em todos(as), o conhecimento descomprometido da arte.

A arte do encontro, no encontro da história, na Conceição das Crioulas tudo que se aprende, aprende-se no fazer, no praticar, no agir, no aprender, no contar, no falar, no cantar e por sua vez, no refazer, no repraticar, no reagir, no reaprender, no refalar, no recontar, no reaprender (FARIA, 2016, p.18).

Para se entender a abrangência educativa das escolas da comunidade quilombola de Conceição das Crianças, antes de tudo, é preciso entender, o modo esclarecido como a comunidade entendia a intromissão das suas escolas na vida da comunidade e o sentido preciso que as suas falas esclarecem. Márcia do Nascimento, professora da comunidade, escreve:

[...] uma educação escolar protagonizada pelas pessoas da própria comunidade onde estão inseridas, é uma ferramenta capaz de reafirmar a identidade do povo e rumar por caminhos que fortaleçam a sua história, através de processos inerentes ao cotidiano da comunidade, nos diversos espaços educativos onde ela acontece (NASCIMENTO, 2017, p.11).

Nesse caminhar da escuta, e a partir da partilha desse entendimento, foi construído o programa "A arte nas escolas da comunidade', desenhado, construído e participado pelas professoras crioulas e por artistas/professores(as)/ investigadores(as) do Identidades_Colectivo de Acção/Investigação, que se deslocaram para o Quilombo, para vivenciar na comunidade o desenrolar do acontecido. Desse vivido e experimentado decorrem nossas reflexões sobre a Educação Artística. Experiência referida aqui no sentido pleno: "A experiência é o que nos acontece, mas não o que acontece, mas sim o que nos acontece" (LARROSA, 2014, p. 68).

Partilhar o modo como a educação artística se foi introduzindo nas escolas da comunidade quilombola de Conceição das Crianças, onde o conceito aurático da arte nunca penetrou, é ter acesso ao desabrochar no interior do alunado de um reconhecimento dos corpos, de ampliação da própria potência artística e 
das amplitudes sensitivas que detêm, no modo de percepcionarem o mundo, se intrometerem no seu contexto comunitário e se relacionarem com os demais. As professoras e os professores da comunidade a partir dos seus saberes, sensibilidades e consciência identitária, as mestres artesãs e o alunado se misturam nas actividades educativas onde em lugar de se promoverem as habilidades inatas de uns e a genialidade individual de poucos, se procura desenvolver uma consciência de pertença interferente no comum, a partir de_si, em cada sujeito.

A arte hoje é um novo tipo de instrumento, um instrumento para modificar a consciência e organizar novos modos de sensibilidade (SONTAG, 1987, p. 341).

A nossa imersão nas escolas de Conceição das Crioulas, perto das suas pedagogias crioulas e de seus modos endógenos de fazer, mas também da referida experiência em Cabo Verde e em Moçambique nos confrontam connosco mesmos, implicando no nosso esforço crítico de entendimento do modo como nos movemos. A interferência das políticas e práticas da Associação Quilombola de Conceição das Crioulas (AQCC) nas escolas, a partir do cruzamento de artes populares em objetos que contam a história coletiva, nos serve para duvidar, perguntar e desmontar o nosso confortável lugar ocidental, patriarcal e capitalista, que isola a arte da vida, a coloca num altar, perante a contemplação reverente e a inacessibilidade. No entanto, é a cultura ocidental expandida em tempos de capitalismo_global que tende a integrar os discursos de resistência e afirmação comunitária num ciclo de paternalismo, exotismo e sedução, tende a aniquilar as aprendizagens que se podem adquirir neste relacionamento intercultural. A educação artística é frequentemente convocada e instrumentalizada em favor deste discurso de integração, esteticização e folclorização do diverso e plural.

Por isso, consideramos a urgência da construção de um entendimento crítico, divergente e transformador, decolonial da Educação Artística. Diferenciada e interferente no que no presente se podem inscrever, em grandes blocos, os dilemas que os conceitos de Educação Artística enfrentam:

- entre entender o ensino artístico como mais um dispositivo de criação de sujeitos que se governem a partir do modo como são governados, ou então procurar entendê-lo como um lugar de desobediência e de possibilidade educativa para que cada sujeito adquira por si, uma consciência de si, da potência de sua interferência social;

- entre confinar o ensino artístico a um espaço onde se persegue a busca da criação artística individualizada e genial, alimentada pelo domínio dos saberes apresentados por uma figura de mestre_educador(a) e pela apre- 
ndizagem do conhecimento já realizado e legitimado, ou o libertar para a promoção de experimentações performativas do alunado, acordando os corpos para a sua potência interferente, sensorial e interpretativa, criativa e realizadora, ativando seus modos críticos de participar nos arredores;

- ou se acomodar num identificar numa visão isolada entre a educação artística focada na presença substantiva da Cultura Visual, ou se apenas se deve recolher perante a Arte, como substância de promoção da educação artística;

- ou então, pugnar pela exigência da presença de artistas nas escolas, atraindo para um evento educativo performático os anseios de massagem do ego autoral de futuros(as) artistas e estabelecendo renovada relação do velho procedimento educativo entre o mestre e o aprendiz, colocando os professores nesse lugar do aprendiz;

- ou conformar o sentido da educação artística no estabelecer estratégias de formação de artistas nuns e formar espectadores seduzidos pelo esplendor social das Artes e da Cultura legitimada pelos dispositivos hegemónicos de poder;

- e, circunscrever o artístico ao serviço dos modelos de desenvolvimento capitalista, colonialista e machista em curso, ignorando as dinâmicas endógenas resilientes e concentradas na construção de um outro devir_comum.

Se nas escolas em Portugal se vivem estas tensões da educação artística, o deslocamento delas para geografias outras, revela-as ainda mais contrastantes e desasjustadas no mundo contemporâneo que vivemos, prefazendo uma receita e curso de massificação de um discurso da educação artística, ora num fazer não pensante, ora num pensar-fazer alienado pelo que o sistema educativo e o mundo da arte permite, persegue e legitima.

\title{
Imagens
}

\author{
$[\ldots]$ \\ O melhor ainda, o mais velhinho \\ e garantido é começar pela palavra \\ eu. Será umbilicalista, egoísta, \\ eu sei cá, mas é pequenina e humilde \\ e não diz mais do que diz, não tem \\ mais responsabilidades do que as que convém
}


seu minúsculo e modesto universo. Para quê querer incendiar os astros se, dentro de nós, ainda não acendemos todas as luzes? (KNOPFLI , 2003, p. 192)

A imagem que temos de nós, das nossas práticas, políticas e estruturas de educação artística, quer nas escolas, museus e centros culturais fruto do espaço geográfico a que associamos o desenvolvimento civilizacional, levam-nos a viajar tendencialmente com uma bagagem assética, racional cuja matéria de construção assenta na superioridade científica e geopolítica hegemónica.

Quando falamos em nos deslocarmos para o Sul político, é mais no sentido de nos deslocarmos de nós, da bagagem que comportamos e entendermos o fracasso que carregamos a partir da ideologia histórica ocidental que nos integra, mesmo não querendo, desempenhando o papel de coloniais paternalistas, eternamente salvadores e salvacionistas. O olhar que é exercido sobre nós por quem nos acolhe, reforça a ambivalência da nossa presença, mobilizada para a necessidade de deixarmos de ser obedientes inconscientes e melhor entendermos a possibilidade de atuação cúmplice.

\footnotetext{
El neoliberalismo es un dispositivo de poder que busca la dominación manipulando y reforzando la obediencia inconsciente, opera activamente para el sometimiento y la dependencia, conseguindo la complicidad de una subjetividad colonizada que actúa cumpliendo con los mandatos y en contra de los propios intereses (MERLIN, 2019, p. 32).
}

Incorporamos um conjunto de modos de pensar e agir que nos acompanham nesse esforço de deslocação da bagagem das relações interculturais, solidárias entre povos. O pressuposto de que a deslocação é para nos repensarmos, melhor entendermos e nos reconhecermos e não para que se reproduza o nosso fracasso.

A disponibilidade para o questionamento do nosso próprio lugar, abre a possibilidade de aprender com o que no sul político gera atrito ao modo hegemónico de entender a educação artística, nomeadamente na fidelização às diretrizes da Organização das Nações Unidas para a Educação, a Ciência e a Cultura (UNESCO) com o Roteiro para Educação Artística e outros modelos de governação dos corpos e das mentes. Esse atrito é o esforço por uma educação artística que resolva os problemas gerados pela própria condição histórica de espaço e gentes antes colonizadas, a partir não de ideias de formação neoliberal, mas de um horizonte cujo bien vivir, digno de todes na sua especificidade e diferença não é excluído. 
Para falar do Bem Viver, é preciso recorrer às experiências, às visões e às propostas de povos que, dentro e fora do mundo andino e amazônico, empenharam-se em viver harmoniosamente com a Natureza, e que são donos de uma história longa e profunda, ainda bastante desconhecida e, inclusive, marginalizada. Foram capazes de resistir, a seu modo, a um colonialismo que dura mais de quinhentos anos, imaginando um futuro distinto que muito poderia contribuir com os grandes debates globais (ACOSTA, 2016, p. 19-20).

Assim, associamo-nos à comunidade quilombola de Conceição das Crioulas, cúmplices de um lugar para que a educação artística se disforme em favor da plasticidade que as lutas do quilombo obrigam face aos repetidos silenciamentos e opressão a que são submetidos. Debruçamo-nos sobre a força política que as conquistas educativas da comunidade, quer na implementação do Projeto Político Pedagógico, elaborado por toda a comunidade para as escolas locais - por elas concebido e constantemente discutido no fazer diário da comunidade; quer nos ensinamentos das mulheres líderes pós graduadas que legitimaram um saber fazer crioulo tanto com a luta diária quanto com na educação, devolvendo à comunidade as suas pesquisas realizadas no Mestrado Profissional em Sustentabilidade Junto a Povos e Territórios Tradicionais, da Universidade de Brasília (UnB) e o obtido reconhecimento científico.

A partir de suas implicações na comunidade e no Ensino implementado, mulheres guerreiras e professoras oferecem através das suas dissertações a leitura crítica de suas falas: Givânia Maria da Silva (2012), Márcia Jucilene do Nascimento (2017), Maria Diva da Silva Rodrigues (2017), Cida Mendes (2019).

\begin{abstract}
A aprendizagem em contexto promovida através do envolvimento de professores e estudantes em projetos de desenvolvimento local do Atelier Mar, bem como projetos de extensão do próprio M_EIA, constituem a possibilidade de gerar um Conhecimento Indisciplinado, pulando fronteiras com o propósito de contribuir para a resolução dos problemas encontrados, como avanço no ponto Aprender a partir de uma compota de papaia (RAINHO, 2018, p. 32).
\end{abstract}

Também nas ilhas de Cabo Verde aprendemos como historicamente a relação do povo com o território de terra e mar, como as suas matérias primas lhe permitiram sobreviver. Essa âncora influenciou, logo após a independência, cooperativas culturais que, resistindo ao estado de abandono colonial, deram corpo a projetos projetos pedagógicos e culturais muito a partir do que essa con- 
dição geográfica forjou. O reconhecimento e pesquisa da prática artesanal nas ilhas desse então determinou o entendimento e a continuidade desses projetos hoje, nomeadamente com o Instituto universitário de Arte, Tecnologia e Cultura (M_EIA), nascido a partir da Organização Não Governamental Atelier Mar, e do Centro Nacional de Arte, Artesanato e Design (CNAD ) que retoma o trabalho da Cooperativa Resistência. A investigação desses dois corpos constituem a base do importante movimento insular de procura de absorção de tecnologias e saberes ancestrais para a renovação do sentido da atuação da educação artística e na promoção de um desenvolvimento endógeno e sustentável.

O movimento que a partir destas instituições foram provocados, se difundem no presente em projectos diversos e utópicos, como o da 'Neve Insular', ou a intervenção urbana, política e cultural que se desencadeia no Alto de Bomba ${ }^{5}$, prolongamento autónomo das intervenções educativas (Campos de Estudo) promovidas pelo M_EIA. A fusão dos procedimentos educativos numa imersão em 'projectos comunitários', regista uma longa lista, onde se destacam pelo envolvimento do M_EIA e do Atelier Mar com as comunidades os 'projecto de desenvolvimento comunitário de Lajedos' na ilha de Santo Antão, de criação do 'Museu da pesca, em S. Nicolau, em Chã das Caldeiras, na ilha do Fogo, ou da Preguiça, na ilha de São Nicolau. O percurso formativo do M_EIA, permitiu vivenciarmos a dinâmica criada pela destruição das fronteiras disciplinares, o abandono da 'sala de aula' e a imersão da aprendizagem na resolução de problemas das comunidades. No tecido do ensino artístico vivenciado no presente na cidade do Mindelo se enfrenta a complexidade existente entre os desejos utópicos de uma educação artística mergulhada na realidade e promotora do fortalecimento educativo do alunado, e as malhas administrativas vinculadas a conceitos herdados do colonialismo.

Hoje são as mulheres que levantam as vozes e clamam contra outras escravaturas. Arremessando ao vento a amargura dos séculos. Queimando os aventais, amolgando panelas, partindo as vassouras, abandonando os tanques de roupa e as tábuas de engomar, para se tornarem cantoras de sonhos (CHIZIANE, 2008, p. 299).

Nossas deslocações para Moçambique, de muitos anos, são as que nos atrapalham o discernimento, e mais fragilizam a nossa consciência, ao apresentarem

5 Alto de Bomba, lugar da periferia da cidade do Mindelo, onde se promove um programa de reabilitação urbana, promovido pelo Ministério de Infraestruturas, Ordenamento do Território e Habitação, envolvendo a comunidade. 
dificuldades múltiplas de leitura, perante a presença da forte e rica ancestralidade cultural, ainda persistente, embora fortemente abalada por ter sido cortada com a tomada das terras pelos portugueses a partir do século XV, pelo roubo das riquezas e o desumano roubo dos corpos que a escravatura fez deslocar para as Américas. Moçambique conquista sua independência em 1975, pela luta anticolonial movida pela Frente de Libertação de Moçambique (FRELIMO), dirigida por Eduardo Mondlane e Samora Machel, transportando os desafios políticos que suas palavras expressavam:

\begin{abstract}
A libertação não significa para nós simplesmente a expulsão dos portugueses; significa reorganizar a vida do país e lançá-la na via do sólido desenvolvimento nacional. Para isso é necessário tirar o poder político das mãos dos portugueses, visto que estes se opuseram sempre ao progresso social e estimularam somente aquele desenvolvimento económico que podia beneficiar uma elite pequena e quase exclusivamente estrangeira. Mas o movimento de libertação não poderá reivindicar o êxito até que, através dele, o povo consiga que os portugueses lhe recusaram: nível de vida tolerável; instrução; condições de desenvolvimento económico e cultural; oportunidade de participar no seu próprio governo (Eduardo Chivambo Mondlane apud ZAWANGONI, 2007, p. 15).
\end{abstract}

As lutas de libertação construíram um movimento coletivo de resistência cuja potência se mantém no esforço pela sobrevivência, autonomia e preposição endógenas, mas simultaneamente dependentes de mecanismos interferentes nas políticas nacionais, presentes com a capa de apoio internacional, sendo preponderante as 'ordens' do Banco Mundial e Fundo Monetário Internacional (FMI). O logro dos apoios internacionais determina as relações externas do continente africano, em particular antigas colónias, uma imposição condicional nos campos do direito, da política, da educação, entre outros, confirmando uma concepção imperial de África. Ou seja, percebemos a conformação de mecanismos de financiamento encobridores de novas formas de colonização, ludibriadores de mentes com discursos emancipadores, mas dominada por práticas opressoras e conservadoras veladas pela cooperação internacional e pela missiva do apoio financeiro. No caso de Moçambique, o eclodir no pós-independência de uma guerra fratricida patrocinada por interesses geo_estratégicos internacionais, durante década e meia mais impossibilitaram o livre desenvolvimento político, social, educacional, cultural.

Esta crítica às estruturas de manutenção das relações de poder e subserviência internacional, projectam-nos numa atenção às políticas e práticas hegemónicas dos países independentes, mas também no pensar/fazer colonizador que 
permanece em nossos corpos e nos corpos dos descolonizados. Este pensar/fazer está muito vinculado à formatação capitalista do viver, com uma base global de consumo e alienação, não só de produtos, como de ideias cujos modelos hegemónicos já revelaram seu fracasso no Ocidente, mas se mantêm como referência imposta para a obrigatória necessidade de 'desenvolvimento' que já referimos. A educação artística vê-se ela própria mergulhada num mar de sujeição, de pertença ao mundo de consumo globalizado, imagens e mundos iguais que todes aspiramos para alcançar as metas das narrativas de sucesso.

Na nossa proximidade às escolas artísticas de Moçambique, ENAV e ISArC, nosso cuidado residia numa colaboração dialética entre não contrapor aos desejos naturais de se implementarem modelos escolares ocidentalizados, nosso pensamento crítico, nem deixar de apresentar, de modo agonístico mas evitando o poder de nossos corpos, nossas sugestões, e de participar nas suas acções.

A forte tradição artística tem-nos ensinado que pouco ou nada sabemos da subversão e submissão por trás da chamada 'arte africana'. E é sempre preciso entender esta problemática na necessária presença da arte produzida em Moçambique no campo expandido da Arte Contemporânea. Ela origina uma necessidade de se impor, na sua renovação, através da formação artística nas suas escolas. O caminho percorrido é expressivo de significação, a evolução em curso com a criação de cursos de formação de professores de artes e a introdução no currículo escolar de disciplinas de formação artística acentua os desafios que um tão largo país enfrenta. Este espaço de discussão que se intensifica em Moçambique deve mobilizar nossas atenções: "A Arte Contemporânea afirma uma forma de intervir no mundo. É um comentário que o Artista faz ao mundo em que vive. É o que acontece no mundo todo. Mas, aqui, temos muito medo" (COSTA, 2021, s.p.).

\title{
Porvir
}

\begin{abstract}
Hay en el colonialismo una función muy peculiar para las palabras: ellas no designan, sino que encubren. Por eso la descolonización no puede ser sólo un pensamiento o una retórica, porque las palabras suelen desentenderse de las prácticas. (CUSICANQUI, 2010, p. 6)
\end{abstract}

Nossos corpos tentam se descobrir, do que conhecem de si e do que desconhecem, encobertos no seu interior, e só vislumbrados pelo confronto a que se disponibilizam, e que procuram, nas suas deslocações, na escuta, na construção de outras memórias. Nesse percurso o que dizemos apenas anuncia o que perseguimos, uma capacidade epistemológica de sermos de corpos inteiros e informa- 
dos anticoloniais, antiracistas, antipatriarcais, ...

[...]Amanhã te direi as palavras, ou depois de amanhã...

Sim, talvez só depois de amanhã...

O porvir... Sim, o porvir... (Álvaro de Campos -Adiamento -PES-

SOA, 1993, p. 266)

\section{Referências}

ACOSTA, Alberto. O bem viver: uma oportunidade para imaginar outros mundos. São Paulo: Editora Elefante, 2016.

ADICHIE, Chimamanda Ngozi Sejamos todos Feministas. Lisboa: Companhia das Letras, 2015.

AMARO, Rogério Roque. Desenvolvimento e injustiça estrutural. COMMUNIO, a. VII, n. 5, p. 448-459, 1990.

APPADURAI, Arjun. Diálogo, Risco e Convivialidade. In: AAVV. Podemos viver sem o outro? Lisboa: Edições Tinta da China e Fundação Calouste Gulbenkian, 2009 .

BÂ, Amadou Hampâté . A tradição viva. In: UNESCO. História Geral da África. v. I. Lisboa: Editora Ática, 2010. p. 183-185

BORGES, Jorge Luis. Aleph. Lisboa: Editora Planeta DeAgostini, 2001.

CASTRO, Eduardo Viveiros de. Metafísicas canibais: Elementos para uma antropologia pós-estrutural. São Paulo: Ubu Editora, 2018.

CHIZIANE, Paulina. O Alegre Canto da Perdiz. Lisboa: Editorial Caminho, 2008. COSTA Alda. A Arte Contemporânea está além da representação linear do mundo: Entrevista. LITERATAS, Revista de Artes e Letras de Moçambique. Disponível em: http://literatasmz.org/post-detail/180 Acesso em: 30 mai. 2021.

CRAVEIRINHA, José. Maria. Maputo: Ndjira, 1998.

CUSICANQUI, Silvia R. Ch'ixinakax utxiwa: una reflexión sobre prácticas y discursos descolonizadores. Buenos Aires: Tinta Limón, 2010.

FANON, Frantz. Os Condenados da Terra. Lisboa: Livraria Terra Livre, 2015.

FARIA, Elisabete Mónica Moreira. Educação Artística Diferenciada: contando 
e recontando a história. Aprender fazendo com/para/na comunidade quilombola de Conceição das Crioulas. Tese de Doutoramento. Faculdade de Belas Artes da Universidade do Porto. Porto, 2016. Disponível em: https://repositorio-aberto. up.pt/handle/10216/85718 Acesso em: 30 mai. 2021.

KI-ZERBO, Joseph. Para quando a África?: entrevista com René Holenstein. Rio de Janeiro: Pallas, 2006.

KNOPFLI, Rui. Obra Poética. Lisboa: Editorial da INCM, 2003.

LARROSA, Jorge. Tremores: escritos sobre experiência. Belo Horizonte: Grupo Autêntica, 2014.

MARTINS, Vítor. Pensem nisso. In: Catálogo da exposição José Paiva - Pintura. Porto: Serpente Galeria de Arte Contemporânea, 2005.

MATTOSO, José. Tenho uma visão pessimista do terceiro milénio: Entrevista. Revista História, a.XXII, p. 14-19, fev., 2000.

MBEMBE, Archile. Políticas da Inimizade. Lisboa: Antígona Editores Refratários, 2016.

MENDES, Maria Aparecida. Marias Crioulas: emancipação e aliança entre mulheres no enfrentamento à violência doméstica em comunidades tradicionais. 2019. Dissertação (Mestrado em Desenvolvimento Sustentável). Universidade de Brasília, Brasília, 2019. Disponível em: https://repositorio.unb.br/handle/10482/37900 Acesso em: 30 mai. 2021.

MERLIN, Nora. Mentir y colonizar.Obediencia inconsciente y subjetividad neoliberal. Buenos Aires: Letra Viva, 2019.

PESSOA, Fernando. Poesias de Álvaro de Campos. Lisboa: Ática, 1993.

NASCIMENTO, Márcia Jucilene do. Por uma pedagogia crioula: memória, identidade e resistência no quilombo de Conceição das Crioulas - PE. 2017. Dissertação (Mestrado em Desenvolvimento Sustentável). Universidade de Brasília. Brasília, 2017. Disponível em: https://repositorio.unb.br/handle/10482/31319 Acesso em: 30 mai. 2021.

RAINHO, Rita. Descolonizar o conhecimento: políticas e práticas de educação artística no ensino superior em Cabo Verde. Tese de Doutoramento. Faculdade de Belas Artes da Universidade do Porto. Porto, 2018. Disponível em: https:// repositorio-aberto.up.pt/handle/10216/117973 Acesso em: 30 mai. 2021. 
RODRIGUES, Maria Diva da Silva. Política de nucleação de escolas: uma violação de direitos e a negação da cultura e da educação escolar quilombola. 2017. Dissertação (Mestrado em Desenvolvimento Sustentável) - Universidade de Brasília, Brasília, 2017. Disponível em: https://repositorio.unb.br/handle/10482/31321 Acesso em: 30 mai. 2021

SILVA, Givânia Maria da. Educação como processo de luta política: a experiência de "educação diferenciada" do território quilombola de Conceição das Crioulas. 2012. Dissertação (Mestrado em Educação)—Universidade de Brasília, Brasília, 2012. Disponível em: https://www.repositorio.unb.br/handle/10482/12533 Acesso em: 30 mai. 2021

SONTAG, Susan. Contra a Interpretação. Porto Alegre: L\&PM, 1987.

SOUZA, Maria Aparecida de Oliveira. As mulheres, a comunidade de Conceição e suas lutas: histórias escritas no feminismo. 2006. Dissertação (Mestrado em História)-Universidade de Brasília, Brasília, 2006. Disponível em: https://repositorio.unb.br/handle/10482/2333 Acesso em: 30 mai. 2021

ZAWANGONI, Salvador André. A Frelimo e a formação do homem novo. Maputo: CFM, 2007. 